\title{
A TEORIA DAS INSTITUIÇÕES E DA MUDANÇA INSTITUCIONAL DE DOUGLASS NORTH: CULTURA, ESTADO E DEPENDÊNCIA DE TRAJETÓRIA
}

\author{
Eduardo José Monteiro da Costa ${ }^{1}$
}

\section{INTRODUÇÃO}

A Nova Economia Institucional (NEI), para além de seus impactos no campo da teoria, historiografia e desenvolvimento econômico, influenciou decisivamente nas últimas três décadas os estudos sobre estratégias, estrutura, atores, processos, relações e poder intrínsecos ao Estado, bem como a administração e prescrição de políticas públicas. Não por acaso, Douglass North, considerado uma das principais referências dessa escola de pensamento, foi agraciado em função de sua contribuição neste campo do conhecimento com o Prêmio Nobel de Economia no ano de 1993.

Nascido em Cambridge, Massachusetts, no ano de 1920, North obteve o seu doutorado em economia na Universidade da Califórnia em Berkeley em 1952. Lecionou na Universidade do Estado de Washington (Seattle) de 1950 a 1983, quando assumiu a titularidade da cátedra Henry R. Luce of Law and Liberty do Departamento de Economia da Universidade Washington (St. Louis, Missouri), a ocupando até o seu falecimento em novembro de 2015 aos 95 anos. Desde cedo demonstrou interesse pelos estudos na área de história econômica, sendo um dos pioneiros nos Estados Unidos a aplicar o instrumental analítico neoclássico com o uso de métodos quantitativos para a análise da historiografia econômica. Por isso é considerado um dos precursores da Nova Escola Histórica, também conhecida como Cliometria - uma alusão à deusa mitológica grega Clio, musa da história (Salama, 2009).

Todavia, após ter elaborado estudos neste campo do conhecimento percebeu as limitações de seu ferramental analítico que, segundo ele: em função de sua natureza a-histórica não consegue explicar com eficiência os motivos que levam a diferentes performances das economias ao longo do tempo; possui limitações importantes em seus pressupostos como a suposição de que as trocas ocorrem num mundo sem fricções, sem custos de transação, com os direitos de propriedade perfeitamente especificados, com informações fluidas e de conhecimento pleno pelos agentes, além de se basear no princípio racional e maximizador do homo oeconomicus; confunde as consequências do crescimento econômico com as suas causas; omite em suas análises a natureza da coordenação e cooperação humanas; e, negligencia 0 papel das instituições e o papel que o altruísmo, ideologias, questões éticas, morais, políticas e

\footnotetext{
1 Bacharel em Economia pela UFPA, Mestre e Doutor em Economia pela Unicamp e professor da Faculdade de Economia e do Programa de Pós-Graduação em Gestão Pública do Núcleo de Altos Estudos da Amazônia (PPGGP/NAEA), ambos da UFPA
} 
religiosas possuem na motivação do comportamento dos agentes. Assim, partindo da premissa de que o mundo econômico é não-ergódico - portanto passivo de mudanças contínuas, inusitadas e atípicas, no qual os agentes precisam de um amplo esforço cognitivo para compreensão dos fenômenos econômicos e sociais (North, 2005; Lopes, 2013) -, e tendo também como objetivo o aperfeiçoamento do instrumental analítico neoclássico, North lançou-se no desafio de consolidar uma teoria das instituições e da mudança institucional que the permitisse um melhor resultado na análise da dinâmica do desenvolvimento por meio de uma perspectiva histórica.

O impulso inicial na elaboração de uma Teoria das Instituições acontece no ano de 1970 com a publicação dos artigos Institutional Change and American Economic Growth: A First Step Towards a Theory of Institutional Change, publicado em coautoria com Lance Davis (North; Davis, 1970), e An Economic Theory of the Growth of the Western World, publicado em coautoria com Robert Paul Thomas (North; Thomas, 1970). Ao longo desta década, por meio de diversos outros trabalhos, North paulatinamente amadurece a sua compreensão sobre o papel das instituições na dinâmica de desenvolvimento.

Em 1981, ao publicar o livro Structure and Change in Economic History, North demonstra uma clara evolução em relação aos trabalhos anteriores e deixa claro que em seu modelo analítico são as instituições que determinam a dinâmica e o ritmo do crescimento econômico, destacando que as formas de cooperação e competição desenvolvidas pelos seres humanos, bem como os sistemas de aplicação das regras de organização das atividades humanas, são fundamentais para a compreensão das mudanças econômicas ao longo do tempo. Destarte, a teoria das instituições de North (1981) é composta por três elementos, uma teoria dos direitos de propriedade, uma teoria do Estado e uma teoria da ideologia: os direitos de propriedade estabelecem incentivos econômicos individuais e coletivos, ao mesmo tempo em que explicam as formas de organização econômica que os seres humanos estabelecem para reduzir os custos de transação e organização das trocas; o Estado entra em seu modelo na medida em que de um lado especifica e resguarda a estrutura dos direitos de propriedade; a ideologia torna-se elemento analítico importante na medida em que é imprescindível para compreender de que modo as diferentes percepções subjetivas afetam a reação dos indivíduos numa realidade objetiva em transformação.

Em 1990 Douglass North publicou o livro Instituions, Institutional Change, and Economic Performance - Political Economy of Instituions and Decisions como resultado amadurecido de décadas de pesquisas no campo da historiografia econômica e, principalmente, no que diz respeito ao papel das instituições e da mudança institucional na dinâmica de 
desenvolvimento das sociedades. Neste livro North traça as linhas gerais de uma teoria por ele consolidada, sublevando o foco na questão da cooperação humana, em especial as formas de cooperação que possibilitam explicar as diferentes trajetórias logradas pelas nações, algumas de riqueza e prosperidade, outras de pobreza e miséria. Ou seja, é por meio da análise das características das instituições econômicas, políticas e sociais que foram por elas criadas e na forma como evoluíram ao longo do tempo, em suas características culturais que moldaram trajetórias dependentes (path dependence), e na conformação das instituições formais por parte do Estado que parte da explicação sobre as suas trajetórias de longo prazo pode ser encontrada.

A partir desta contribuição seminal a historiografia econômica contemporânea tem cada vez mais incorporado em suas análises estudos sobre as transformações institucionais por que passaram determinadas sociedades e de que forma essas impactaram a espacialidade do desenvolvimento capitalista. Para além das análises historiográficas, esse debate sobre o papel das instituições no desenvolvimento acaba sendo incorporado na agenda de pesquisa de várias escolas de pensamento, impactando decisivamente as suas formulações teóricas - dentre elas podemos destacar as análises do desenvolvimento endógeno, Escola Neo-Schumpeteriana, Escola de Harvard (em especial os trabalhos de Michel Porter) e Nova Geografia Econômica.

A percepção da importância desse debate fez com que ele transcendesse a academia e a partir da década de 1990 passasse a permear o debate do planejamento público, principalmente por meio da incorporação dessa agenda nas ações e prescrições de diversas organizações internacionais como o Fundo Monetário Internacional (FMI), o Banco Mundial e a Comissão Econômica para a América Latina (Cepal/ONU), seja para aprimorar o processo de implantação de políticas públicas ou para melhor compreender o processo de formação econômica e social, e o desnível de desenvolvimento de algumas sociedades em detrimento de outras, com certo destaque dado para as economias da América Latina.

Nesse contexto, se intensifica o debate sobre a explicação do porque a inovação tecnológica acontece em determinados contextos sociais com maior facilidade do que noutros, a relação da cultura com o desenvolvimento, a importância do capital social, a necessidade de consolidação de adequados modelos de governança (seja numa perspectiva pública mais ampla ou no setor privado), a importância da transparência e do accountability para as organizações, 0 debate sobre qual seriam as "boas instituições" ou "boas práticas" que deveriam ser adotadas para o desenvolvimento de uma sociedade, ou mesmo a explicação de simulacros em termos da tentativa de replicação de políticas bem-sucedidas em determinados contextos que fracassam noutras realidades. 
Assim, a teoria das instituições e da mudança institucional de Douglass North acabou tendo significativa influencia tanto no campo acadêmico quanto no processo de análise e prescrição de políticas públicas. Este artigo, portanto, tem por objetivo apresentar os elementos centrais do modelo analítico desenvolvido por Douglass North, em especial o papel que a cultura e o Estado desempenham em sua teoria das instituições e da mudança institucional, bem como na determinação de uma trajetória dependente. Para isso, após essa breve introdução, está dividido em quatro partes. A primeira apresenta a teoria das instituições de North em sua visão consolidada, destacando os seus conceitos mais importantes. A segunda parte tem por finalidade destacar o papel que a cultura possui no processo de determinação das trajetórias sociais de longo prazo. A terceira destaca o papel do Estado em seu modelo analítico, em especial a capacidade que possui de promover mudanças institucionais que podem tornar uma economia mais eficiente, garantindo direitos de propriedade e reduzindo custos de transação e incertezas. E, finalmente, a última parte está reservada a breves considerações finais.

\section{INSTITUIÇÕES E MUDANÇA INSTITUCIONAL: A TEORIA CONSOLIDADA EM DOUGLASS NORTH}

Ao longo das décadas nas quais debruçou-se sobre a análise da historiografia econômica, North distanciou-se progressivamente da Cliometria estabelecendo críticas importantes a elementos dos corpos analíticos do mainstream da teoria econômica ortodoxa, das teorias do crescimento e da teoria do desenvolvimento.

De acordo com North (1993a) a Teoria Neoclássica não consegue explicar com eficiência os motivos que levam as diferentes performances das economias ao longo do tempo. Possui limitações importantes em seus pressupostos como a suposição de que as trocas ocorrem em um mundo sem fricções, sem custos de transação, com os direitos de propriedade perfeitamente especificados e com racionalidade ilimitada, implicando em informações fluidas e de conhecimento pleno por parte dos agentes (Robles, 1998; Azevedo, 2015).

Para além das críticas já elencadas em North e Thomas (1973) sobre as tradicionais teorias do crescimento, apontando que estas confundem as consequências do processo com as causas, North estabelece críticas ao princípio racional e maximizador do homo oeconomicus, afirmando que altruísmo, ideologias, questões éticas, morais, políticas e religiosas possuem papel destacado na motivação do comportamento dos agentes (North, 1981; 1990; 1995a; 2018)

Nem mesmo a teoria do desenvolvimento foi poupada de suas críticas. Segundo ele, mesmo depois de quarenta anos de esforços, as disparidades no desempenho das economias e a sua persistência ao longo do tempo não foram satisfatoriamente explicadas, sobretudo devido 
a omissão em suas análises a respeito da natureza da coordenação e cooperação humanas (North, 1990; 1995a; 2018).

Essa percepção sobre a inconsistência dada pela teoria aos problemas de coordenação e cooperação humanas levou North, da mesma forma, a questionar o modelo da Teoria dos Jogos que, segundo a sua opinião, não parte de uma hipótese de comportamento humano realista. Em sua perspectiva, o comportamento humano, conforme já destacado, é muito mais complexo do que assume a função de utilidade dos modelos econômicos convencionais (North, 1990; 1995a; 2018).

A partir destas constatações e partindo da premissa de que o mundo econômico é nãoergódico - portanto passivo de mudanças contínuas, inusitadas e atípicas, no qual os agentes precisam de um amplo esforço cognitivo para a compreensão dos fenômenos econômicos e sociais (North, 2005; Lopes, 2013; Azevedo, 2015) -, e, também, com o objetivo de aperfeiçoar o instrumental analítico ortodoxo, North lançou-se no desafio de consolidar uma teoria das instituições e da mudança institucional que lhe permitisse obter melhor resultado na análise da dinâmica do desenvolvimento por meio de uma perspectiva histórica. É, neste sentido, a partir do livro Instituições, Mudança Institucional e Desempenho Econômico publicado originariamente em língua inglesa no ano de 1990 que o aporte analítico de Douglass North sobre o papel das instituições e da mudança institucional no desenvolvimento econômico alcança maior nível de maturidade.

North inicia o seu discurso por ocasião do recebimento do Prêmio Nobel de Ciência Econômicas, proferido em Estocolmo na Suécia no dia 09 de dezembro de 1993, afirmando (North, 1993a):

\footnotetext{
A história econômica versa sobre o desempenho das economias no transcurso dos anos. $O$ objetivo das investigações neste campo não é somente permitir que 0 passado econômico se torne mais claro, mas também contribuir para a teoria econômica ao proporcionar um marco analítico que permita compreender a mudança econômica.
}

Seguindo esse desiderato, o ponto de partida de seu modelo é o axioma de que as instituições e a estrutura produtiva herdadas por meio de processos históricos singulares geram dinâmicas socioeconômicas diversificadas entre nações. Isto significa que o desenvolvimento econômico é um fenômeno eminentemente institucional, resultante de complexas interações entre forças econômicas, políticas e culturais da qual fazem parte distintos arranjos institucionais, que conferem diferenças nas trajetórias de desenvolvimento, bem como na forma de organização das diversas organizações da sociedade. Neste sentido, o sucesso ou o fracasso 
das nações decorrem de sua formação histórica e da forma como as suas instituições foram criadas e/ou evoluíram.

Em suma, quando North formula a questão central de sua pesquisa - por que algumas nações adentram em um caminho de prosperidade enquanto outras permanecem na pobreza e na miséria? -, ele encontra a resposta nas instituições e nas organizações que as sociedades constroem ao longo de sua história (North, 1993a). É seguindo esta senda que passamos a apresentar os conceitos fundamentais de sua teoria: instituições, matriz institucional, organizações, dependência de trajetória (path dependence) e ruptura institucional.

As instituições são apresentadas como normas socialmente construídas ("regras do jogo"), gozando de aceitação geral pelos membros de um grupo social, que impõem restrições formais e/ou informais e que moldam o processo de interação, ao mesmo tempo em que estruturam incentivos na troca humana, sejam estes de ordem política, social ou econômica. Ao fazerem isso as instituições reduzem a incerteza na medida em que conferem uma estrutura previsível de ação por meio da coordenação das expectativas divergentes, criando padrões de comportamento duráveis e rotineiros que estabelecem limites para o conjunto de escolhas dos agentes (North, 1990; 1995a; 2018). Conforme North (1991, p. 97):

As instituições são restrições criadas pelos homens que estruturam a interação
política, econômica e social. Elas consistem em restrições informais (sanções, tabus,
costumes, tradições e códigos de conduta) e regras formais (constituições, leis,
direitos de propriedade). Ao longo da história, instituições foram criadas por seres
humanos para criar ordem e reduzir a incerteza nas trocas. Juntamente com as
restrições comuns da economia, elas definem o conjunto de opções e, portanto,
determinam os custos de transação e produção e, portanto, a lucratividade e a
viabilidade de se envolver na atividade econômica. Elas evoluem gradualmente,
conectando o passado com o presente e o futuro; a história em consequência é, em
grande parte, uma história da evolução institucional, na qual o desempenho histórico
das economias só pode ser compreendido como parte de uma história sequencial.
As instituições fornecem a estrutura de incentivos de uma economia; à medida que
essa estrutura evolui, ela molda a direção da mudança econômica em direção ao
crescimento, estagnação ou declínio.

As instituições reduzem - juntamente com a tecnologia empregada - os custos de transação e transformação, bem como o de acesso às informações, envolvidos na atividade humana. Porém, em que pese o principal papel das instituições seja o de reduzir a incerteza, estabelecendo uma estrutura estável para a interação humana, estas não são necessariamente eficientes do ponto de vista social, podendo, consequentemente, os custos de transação, produção e acesso as informações diferirem substancialmente entre as sociedades em decorrência de suas diferentes estruturas institucionais.

Portanto, torna-se conveniente repisar, existe um caráter histórico nas trajetórias das sociedades que deriva da forma como as suas matrizes institucionais foram conformadas e 
evoluíram. Consequentemente, a compreensão das trajetórias de desenvolvimento das nações depende da investigação de sua matriz institucional e, para isso, torna-se necessária a análise da conformação das regras e normas, formais e informais, que a compõem e formam uma rede interligada que, sob variadas combinações, moldam o conjunto de escolhas dos agentes em múltiplos contextos, bem como das instituições que garantem a sua aplicação (enforcement). Essa hipótese leva ao corolário de que, de um lado, o subdesenvolvimento é resultado de instituições socialmente ineficientes e, de outro, somente com uma mudança institucional países subdesenvolvidos conseguiriam romper com a sua trajetória de subdesenvolvimento.

A mudança institucional, ao definir o modo como as sociedades evoluem ao longo do tempo, pode ser até mesmo mais importante para o desenvolvimento, ao estimular o capital físico e humano, do que o acesso a inovações tecnológicas (Gala, 2003a; North, 1990; 1995a; 2018). Nessa análise, as organizações - entendidas como grupos de indivíduos unidos por um propósito comum - inserem-se como elementos dinâmicos do modelo². Ao mesmo tempo em que são influenciadas pelo ambiente institucional na qual estão inseridas, as organizações influenciam a transformação desse ambiente, ao perseguirem os seus objetivos, num processo que molda a evolução institucional da sociedade. Em síntese, se as instituições são as "regras do jogo", as organizações são os jogadores (North, 1990; 1993a; 1994; 1995a; 2018).

North $(1990 ; 1995 a ; 2018)$ ao firmar a compreensão de que as instituições são dependentes de suas trajetórias prévias - portanto "portadoras da história", na medida em que apresentam fortes relações com suas configurações historicamente herdadas (Strachman, 2000) - estabelece a matriz institucional de uma sociedade como o elo de ligação entre o passado e o presente, e como condicionante do futuro por meio de uma dependência de trajetória, moldada por meio da interação entre instituições e organizações, o que realça a importância para a historiografia econômica da compreensão das sequências temporais de eventos e processos sociais, bem como sobre o meio em que esses processos ocorreram e que permitiram a geração de determinada percepção pelos indivíduos, constrangendo-os, ou não, a optarem pelo aproveitamento de "janelas de oportunidades" disponíveis.

O conceito de dependência de trajetória surge, assim, como uma explicação que permite observar a influência do passado sobre o presente e deste sobre o futuro, possibilitando o entendimento das diferenças de desenvolvimento entre países, regiões e cidades, decorrente de processos de auto reforço de suas trajetórias históricas. Assim, uma vez definido um

\footnotetext{
2 De acordo com North (2018) as organizações incluem órgãos políticos (partidos políticos, Câmaras, Senados, Conselhos e agências reguladoras), corpos econômicos (empresas, sindicatos, fazendas, cooperativas e associações patronais), corpos sociais (igrejas, clubes, sociedades filantrópicas e culturais) e órgãos educacionais (escolas, universidades e centros de formação profissional).
} 
caminho, há a atuação de mecanismos auto-reforçantes que fazem com que a matriz institucional fique "trancada" (lock in) em uma trajetória, mutável apenas por meio de uma ruptura institucional. E, caso ocorra por qualquer motivo uma mudança nas estruturas institucionais, altera-se a percepção por parte dos agentes da matriz de incentivos e incertezas, bem como a predisposição à cooperação e os custos de transação sobre o ambiente (North, 2005).

\section{A CULTURA COMO CHAVE PARA A COMPREENSÃO DA DEPENDÊNCIA DE TRAJETÓRIA}

A teoria das instituições e da mudança institucional de North amadureceu ao longo de vários anos de pesquisas e de diversos trabalhos. O livro Instituições, Mudanças Institucionais e Desempenho Econômico, publicado originalmente em língua inglesa no ano de 1990, pode ser considerado como o marco temporal que separa o North em amadurecimento teórico (décadas de 1970 e 1980), do North com uma visão teórica mais consolidada e com concatenamentos analíticos mais complexos entre os seus conceitos fundamentais (décadas de 1990 e 2000).

North e Thomas (1973), ao sinalizarem que diferentes processos culturais poderiam resultar em diferentes histórias econômicas, estabeleceram insights que levariam North a paulatinamente ampliar a sua análise sobre a relação entre as instituições informais e 0 desenvolvimento. Em que pese isso, a noção de indivíduo assumida em boa parte do livro ainda era muito próxima da perspectiva neoclássica, sendo este ainda visto como um átomo social que estabelecia o seu comportamento de forma independente de seu entorno social (Azevedo, 2015).

Em North (1981) é possível observar uma mudança nessa premissa comportamental dos indivíduos, sobretudo, com a introdução em sua análise da ideologia, que funcionaria como elemento simplificador dos processos decisórios, conferindo uma visão específica de mundo ao indivíduo tomador de decisão, e servindo como fator explicativo para a compreensão de estruturas políticas e econômicas ineficientes. Ademais, a combinação das regras constitucionais com os códigos de comportamentos culturais subjacentes, ao mesmo tempo em que dá estabilidade às instituições, torna qualquer dinâmica de mudança demorada e, em regra, apenas incremental. Ou seja, ideologia, normas e convenções sociais, bem como códigos de conduta ética e moral, passaram a ser elementos importantes na análise por interferirem na esfera comportamental dos indivíduos e darem legitimidade, estabilidade e ordem à vida social. No limite, sem os constrangimentos impostos por questões ideológicas, os custos de enforcement seriam inviáveis para às organizações. 
Em North (1990), e alguns trabalhos posteriores, a partir da introdução do conceito de racionalidade limitada, é possível notar significativo avanço na compreensão da dinâmica institucional decorrente do tratamento da cultura como chave para a compreensão da dependência de trajetória. A partir desse ponto, ao invés de proceder a uma análise cronológica de seus trabalhos, optamos - posto entendermos que para efeito de análise e sistematização é mais objetivo e profícuo - por buscar edificar sua visão sobre o papel da cultura no desenvolvimento econômico com base em seus trabalhos mais recentes (décadas de 1990 e 2000).

No conjunto teórico desenvolvido por Douglass North o mundo econômico é não ergódico, apresentando mudanças contínuas, inusitadas e atípicas, e os indivíduos, por meio de modelos mentais preexistentes, processam informações incompletas, num esforço cognitivo de compreensão dos fenômenos econômicos e sociais, que os auxiliam no entendimento do ambiente ao mesmo tempo em que determinam o seu comportamento social, nem sempre movidos por impulsos maximizadores, mas, em muitos casos, pelo altruísmo e por restrições auto impostas (North, 1990; 1995a; 2005; 2018). Nesse sentido, as instituições - por meio de informações socialmente transmitidas em determinado contexto cultural - estabelecem mecanismos de incentivos ou restrições nas decisões dos indivíduos e das organizações (North, 1993b).

Conforme North (1993a):

É necessário desmantelar o pressuposto de racionalidade subjacente à teoria econômica, a fim de abordar construtivamente a natureza da aprendizagem humana. A história nos mostra que ideias, ideologias, mitos, dogmas e preconceitos são importantes; e é necessário compreender o modo como eles evoluem para alcançar maiores avanços no desenvolvimento de um quadro de referência para entender a mudança social.

Desta forma, a teoria das instituições e da mudança institucional desenvolvida por North reserva um papel especial para a cultura no processo de determinação das trajetórias sociais de longo prazo na medida em que a estrutura que governa a interação social cotidiana, passando por relações familiares, ou mesmo no campo do trabalho e dos negócios, é definida em grande medida por restrições informais, códigos de conduta, normas de comportamento e convenções. Estas, ao mesmo tempo em que fazem parte de uma herança cultural, definem a forma como os indivíduos processam e utilizam as informações, bem como tomam as suas decisões por meio de seus modelos mentais. Esses modelos mentais - um constructo advindo das ideias, ideologias e religiões - ao sustentarem crenças que reduzem as divergências entre os indivíduos e garantirem a transferência intergeracional do conhecimento, acabam 
estabelecendo o molde sobre o qual são conformadas as economias e as sociedades (North, 1990; 1993a;1995a; 2005; 2018; North; Denzau, 1994; Lopes, 2013; Azevedo, 2015). ${ }^{3}$

É em decorrência disso que North (1993a) compreende as instituições como representações da consciência dos indivíduos, expressões dos modelos mentais compartilhados e, portanto, representações externas dos modelos cognitivos individuais, que possuem como finalidade a estruturação e a organização de seu meio através da estabilização das ações e da redução da incerteza.

É nesse sentido que North (2003a) destaca que as regras informais acabam se tornando, para a dinâmica das sociedades, até mesmo mais importantes do que as formais. Exatamente por isso que mudanças culturais evolvendo alterações na cosmovisão dos indivíduos, advindas de alterações na ideologia, crenças, valores e religião, abalam a estabilidade das instituições e tendem a ser importantes vetores de mudanças institucionais (North, 1990; 1995; 2005; 2018; Robles, 1998).

Conforme afirma Robles (1998, p. 16):

North considera que a cultura é a chave para a compreensão do fenômeno da "dependência de trajetória" [path dependence], quer dizer, para compreender por que é tão difícil que as economias - uma vez encaminhadas por um caminho de crescimento, ou estagnação, ou declive - logrem reverter sua tendência de longo prazo. North explica que a aprendizagem de qualquer geração está fortemente condicionada pelas percepções derivadas da aprendizagem coletiva secular. Assim, a aprendizagem é um processo cumulativo filtrado pela cultura de uma sociedade.

A cultura, desta forma, torna-se elemento central para explicar a performance econômica e política através do tempo (North, 2005); e, como mencionado, materializa-se, em última instância, como a chave para a dependência de trajetória, na medida em que os indivíduos ao fazerem as suas escolhas o fazem sob influência de suas crenças, formadas por meio de um processo de aprendizagem cumulativo que é transmitido culturalmente de uma geração para outra. ${ }^{4}$ Conforme North (1993a):

Isto é, as crenças mantidas por indivíduos, grupos e sociedades e que determinam suas preferências são uma consequência de sua aprendizagem ao longo do tempo, e não apenas do tempo de vida de um indivíduo ou de uma geração; são a aprendizagem incorporada em indivíduos, grupos e sociedades, cumulativa no tempo e transmitida de uma geração para outra pela cultura de cada sociedade.

\footnotetext{
${ }_{3}^{3}$ Para North (1992), rotinas, costumes, tradições e cultura são termos usados para denotar a persistência de regras ou restrições informais, que incluem: (i) convenções que evoluem como soluções para problemas de coordenação e que todas as partes tem interesse em manter; (ii) normas de comportamento que são padrões de conduta reconhecidos; (iii) códigos de conduta auto impostos, como padrões de honestidade ou integridade.

${ }^{4}$ Conforme North (1993a): "É a cultura que fornece a chave para a dependência da trajetória - um termo usado para descrever a poderosa influência do passado no presente e no futuro."
} 
Portanto, o processo de aprendizagem social advém das experiências socioculturais vivenciadas pelos indivíduos, algo que é constantemente atualizado a partir de impulsos externos (North, 2005). Essa visão também está presente em North, Mantzavinos e Shariq (2004) ao enfatizarem que os modelos mentais são dinâmicos e evoluem com o decorrer do tempo como resultado das experiências vivenciadas pelos seres humanos. Quando considerados adequados para a interpretação do ambiente acabam se estabilizando e modelando um "sistema de crenças", porém, quando se mostram inconsistentes acabam revistos e originam um novo sistema de crenças. North, Wallis e Wingast (2006) destacam que as organizações educacionais e religiosas possuem papel privilegiado na conformação das crenças dos indivíduos e, como consequência, na moldagem das organizações.

É, em função disso, que o foco recai sobretudo no indivíduo como unidade analítica na medida em que a percepção da realidade social acaba sendo resultante de um processo de aprendizagem e do modelo cognitivo individual, formado em um contexto específico e derivado das crenças e percepções advindas de uma estrutura institucional, ideológica, educacional e religiosa disseminada na sociedade.

Derivado desse entendimento é possível afirmar que: (i) o desempenho econômico de uma sociedade é expressão última de suas instituições, moldadas por um processo histórico através da cultura, das crenças, dos modelos mentais compartilhados e dos modelos cognitivos individuais; (ii) os modelos mentais condicionam as ações dos indivíduos, e acabam determinando trajetórias sociais dependentes; (iii) nenhuma mudança institucional ocorre sem 0 suporte de um sistema de crenças pré-existente; (iv) a determinação causal do desenvolvimento segue, portanto, do nível cognitivo, para o institucional e deste para o econômico (North, 2003a; North; Mantzavinos; Shariq, 2004).

\section{O PAPEL DO ESTADO NA TEORIA DAS INSTITUIÇÕES DE DOUGLASS NORTH}

Enquanto Gala (2001) destaca a singularidade das contribuições de North no tocante a ideologia e o Estado, para Fiani (2003) o aspecto mais original da contribuição de North é a questão do papel institucional do Estado e, por isso, em sua avaliação, aquele que concentra todo esforço para o seu aprimoramento na medida em que as economias modernas, fundadas em uma complexa e crescente divisão do trabalho, exigem uma estrutura institucional que dê conta da complexidade nas interações entre os agentes econômicos.

Antes, contudo, de ser apresentada a sua visão amadurecida sobre o Estado (North, 1990; 1993a; 1995a; 2018), rapidamente serão regatados os insights que o autor teve em algumas obras, que permitem, inclusive, perceber que da mesma forma como a sua visão das 
instituições apresentou progressividade analítica, a sua visão sobre o Estado também se aprimorou com o decorrer do tempo.

Em North e Tomas (1973) os autores já enfatizavam que transformações institucionais, ao garantirem ao inovador os direitos de propriedade e as vantagens econômicas das inovações, explicam a ascensão do mundo ocidental. Mas isso não teria ocorrido de forma homogênea, e em função disso questionam: por que os países apresentavam trajetórias institucionais distintas, com alguns sendo bem-sucedidos na criação de instituições indutoras do crescimento e outros não? Respondendo esse questionamento, os autores afirmam que isso somente foi possível em decorrência do poder coercitivo do Estado que, influenciado por grupos políticos, através de intervenções de caráter exta-econômico, estabeleceu instituições indutoras do desenvolvimento, sobretudo, a garantia do direito de propriedade. Ou seja, o Estado ao monopolizar a função de proteção e justiça possui, também, monopólio na definição e na garantia do direito de propriedade, passando a arrecadar impostos em troca destes serviços. Essa troca torna-se vantajosa para todos os agentes fundamentalmente porque o Estado ao lograr economias de escala, fornece esses serviços de forma mais econômica do que se os mesmos fossem ofertados pela iniciativa privada.

\section{Conforme enfatizam os autores:}

O crescimento econômico ocorre se a produção cresce mais rapidamente que a população. Dadas as premissas descritas sobre como as pessoas se comportam, 0 crescimento econômico ocorrerá se os direitos de propriedade fizerem valer a pena a realização de atividades socialmente produtivas. A criação, especificação e promulgação desses direitos de propriedade são caras, em certo grau afetado pelo estado da tecnologia e da organização. À medida que o potencial de ganhos privados excederem os custos de transação, serão feitos esforços para estabelecer esses direitos de propriedade. Os governos assumem a proteção e a aplicação dos direitos de propriedade, porque podem fazê-lo a um custo menor do que os grupos voluntários privados. No entanto, as necessidades fiscais do governo podem induzir a proteção de certos direitos de propriedade que impedem, em vez de promover 0 crescimento; portanto, não temos garantia de que surgirão fecundos arranjos institucionais. (North, Thomas, 1973, p.8)

Seguindo essa linha North (1981) enfatizou que o nível de renda é maior nas sociedades nas quais o Estado garante o direito de propriedade, dada as economias de escala que possui, do que nas sociedades nas quais os governados têm de por si mesmo prover essa garantia 5 . Ademais, conforme bem enfatizado por Fiani (2003), o Estado tenta agir como um monopolista discriminador, separando grupos para atribuir direitos de propriedade que maximizem a sua receita fiscal na medida em que a redução dos custos de transação

\footnotetext{
5 North (1981) afirma que a diferenças nas taxas de crescimento do países europeus durante o século XVII encontra-se na natureza dos direitos de propriedade desenvolvidos em cada Estado-Nação.
} 
potencializa a produção máxima da sociedade. É em consonância com essa visão que encontramos em North (1981, p. 22) uma definição de Estado:

\begin{abstract}
Um estado é uma organização com uma vantagem comparativa em violência, estendendo-se por uma área geográfica cujas fronteiras são determinadas por poder aos constituintes fiscais. A essência dos direitos de propriedade é o direito de excluir, e uma organização que tem uma vantagem comparativa na violência está em posição de especificar e fazer valer os direitos de propriedade.
\end{abstract}

North (1981), aditivamente, afirma que uma teoria do Estado é essencial na medida em que o mesmo é diretamente responsável pelo desempenho da economia, de um lado por especificar a estrutura dos direitos de propriedade e garantir a sua eficiência, de onde decorre as origens do crescimento, estagnação ou declínio econômico; de outro, por deter discricionariedade em alterações institucionais, o que faz com que o autor enfatize que as iniciativas de reformas nas instituições devem partir com mais frequência dos governos. Indo mais além, os direitos de propriedade estabelecidos são o resultado de tensões que envolvem os interesses dos governantes e os esforços dos agentes para redução dos custos de transação. Assim, há a sinalização de que grupos de pressão tentam influenciar os tomadores de decisão para a alteração das "regras do jogo" da concorrência e da cooperação, influenciando a estrutura dos mercados de fatores e de produtos.

North (1989) volta a destacar a importância do Estado na promoção da eficiência nos mercados de produtos e fatores e na garantia dos direitos de propriedade, ao definir, regulamentar e fiscalizar as regras formais da economia. Mas é em seu livro lançado originalmente em língua inglesa em 1990 e em seu discurso por ocasião do recebimento do Prêmio Nobel de Economia em Estocolmo em 1993 que a sua análise sobre o papel do Estado alcança maior nível de amadurecimento. Conforme Fiani (2003, p. 145):

A evolução do pensamento de Douglass North com relação ao papel institucional do Estado na economia alcançou seu ponto culminante em sua obra Institutions, Institutional Change and Economic Performance (North, 1990), quando ele se afastou da noção de Estado construída em seu livro anterior, Structure and Change in Economic History (North, 1981), o seu "modelo neoclássico de Estado.

Em North (1990; 1995a; 2018) há claramente um esforço de aproximação do ambiente econômico com o plano político superando a visão de que os governantes agem apenas com 0 interesse de maximizar receitas fiscais e de que a sociedade busca apenas reduzir custos de transação mediante a garantia de direitos de propriedade. Aparentemente, em parte, North procura corrigir uma deficiência analítica que o seu modelo apresentava que era o difícil enquadramento nas democracias modernas, pautadas pela complexidade oriunda da diferenciação crescente das visões de mundo dos agentes e do pluralismo político e ideológico. Essa diversificação das pautas sociais acaba exercendo múltiplas influências na burocracia 
estatal - com a própria burocracia estatal podendo se converter, em certas circunstancias, num importante grupo de pressão - ao mesmo tempo em que exigem um esforço mais amplo para a definição de regras e garantia de seu cumprimento (North, 1990; 1995a; 2018; Fiani, 2003).

A influência exercida pelos grupos de pressão passa a ter destaque na análise de North na medida em que a simbiose de seus interesses com os da burocracia estatal pode influenciar decisivamente a conformação da matriz institucional da sociedade. Conforme North (1990, p. 47):

\begin{abstract}
A estrutura existente de direitos (e o caráter de sua aplicação) define as oportunidades existentes de maximização da riqueza dos jogadores, que pode ser realizado através da formação de intercâmbios econômicos ou políticos. A troca envolve pechinchas feitas dentro do conjunto existente de instituições, mas igualmente os atores às vezes acham que vale a pena dedicar recursos para reorganizar a estrutura mais básica da política para reatribuir direitos.
\end{abstract}

Nesse sentido, faz parte das democracias modernas a pressão de grupos de interesses sobre o Estado e sobre a burocracia estatal, ou até mesmo ações em prol de mudanças na estrutura política de uma sociedade com a finalidade de redefinir regras e direitos de propriedade, e com isso a repartição dos ganhos. Indo mais além, na medida em que o Estado detém força coercitiva, aqueles que dirigem o governo podem usar essa força em benefício de seus interesses em detrimento dos interesses do resto da sociedade.

Finalmente, em seu discurso em Estocolmo Douglass North retoma, reforça e amplia alguns pontos.

Para North (1993a) as organizações políticas modelam o desempenho econômico porque definem e implementam regras econômicas. Nesse sentido, em sua visão, uma política de desenvolvimento efetiva perpassa pela criação de organizações políticas capazes de criarem e de imporem direitos de propriedade eficientes. Conduto, a criação de organizações políticas ainda é um campo regado a incertezas na medida em que grande parte do conhecimento da chamada Nova Economia Política - um campo de conhecimento emergente que segundo North deriva da NEI aplicada à política - focou prioritariamente na realidade dos Estados Unidos e nas organizações políticas deste país. É nesse sentido que já em 1993 North apontava como uma agenda importante as pesquisas sobre as características e a moldagem de organizações políticas no Terceiro Mundo e na Europa Oriental.

North (1993a) em seu caráter prescritivo aconselha que ao se elaborar políticas de desenvolvimento para o Terceiro Mundo e Leste Europeu se tenha por parâmetros os fundamentos do enfoque institucional-cognitivo, na medida em que o ambiente cultural, os hábitos e costumes, valores, ideologias, podem alterar o efeito resultante das regras formais. 
Assim, a simples transferência de regras formais podem não lograr o efeito esperado, resultando em simulacros de políticas públicas. Conforme Robles (1998, p. 16):

Em primeiro lugar, recomenda ter em mente que a simples transferência de regras formais - políticas e econômicas - de economias de mercado exitosas para economias atrasadas ou em transição não é condição suficiente para alcançar um bom desempenho econômico, já que os resultados econômicos dependem também das regras informais (que mudam gradualmente) e da aplicação das regras (cujo custo está determinado, em boa medida, pelas regras informais).

Outro ponto enfatizado é a necessidade de fortalecimento do Estado para que 0 mesmo tenha capacidade de estabelecer e aplicar regras econômicas eficientes. Por conseguinte, dentre as principais condicionantes para o desenho de instituições indutoras do crescimento destacam-se (North, 1993a):

i) as instituições políticas serão estáveis apenas se forem apoiadas por organizações comprometidas com sua perpetuação; ii) para alcançar uma reforma bem-sucedida, as instituições e os sistemas de crenças devem mudar, já que são os modelos mentais dos atores que irão moldar as decisões; iii) o desenvolvimento de normas comportamentais que apoiam e legitimam novas regras é um processo longo e, na ausência desses mecanismos de reforço, as organizações políticas tenderão a ser instáveis; iv) enquanto o crescimento económico pode ocorrer a curto prazo com regimes autocráticos, o crescimento a longo prazo implica o desenvolvimento do estado de direito; v) Ocasionalmente, limitações informais (normas, convenções e códigos de conduta) que favorecem o crescimento produzem crescimento econômico mesmo com normas políticas instáveis ou adversas. A chave é o grau em que essas regras adversas são impostas.

Convém, outrossim, chamar atenção para a recomendação de se desenvolver estruturas institucionais flexíveis capazes de se adaptarem e suportarem choques e mudanças, sem maiores fricções institucionais. Conforme North (1993a):

A chave para o crescimento no longo prazo é a eficiência da adaptação, e não a eficiência da distribuição. Sistemas políticos e econômicos bem-sucedidos desenvolveram estruturas institucionais flexíveis que podem sobreviver aos choques e mudanças que fazem parte do desenvolvimento próspero. Mas esses sistemas têm sido o resultado de uma longa gestação. Não sabemos como criar eficiência de adaptação no curto prazo.

Finalmente, a influência da tese desenvolvida por Douglass North no campo da relação entre instituições, Estado e desenvolvimento é notada claramente no Informe do Banco Mundial de 1997, Informe sobre o desenvolvimento mundial: O Estado em um mundo em transformação, documento da qual o autor foi um dos consultores, e que em seu capítulo segundo, denominado Atenção renovada a eficácia do Estado, estabelece o marco analítico de todo o documento ao mesmo tempo em que prescreve orientações de políticas, sobretudo, para os países subdesenvolvidos. 


\section{CONSIDERAÇÕES FINAIS}

North, a partir das críticas formuladas ao mainstream da ortodoxia econômica, paulatinamente afasta-se de Cliometria e passa a desenvolver um corpo teórico que se propôs a superar as limitações dessa matriz analítica, e o faz com certo brilhantismo, tanto que passa a ser um dos maiores expoentes da NEI e, por sua contribuição nesse campo, acabou laureado com o Prêmio Nobel de Economia em 1993.

A pesquisa desenvolvida por Douglass North impactou significativamente a teoria econômica contemporânea ao destacar a importância das instituições e da mudança institucional para análise da dinâmica de desenvolvimento das sociedades ao oferecer um ferramental analítico capaz de buscar evidências sobre o porquê algumas nações adentraram numa trajetória de desenvolvimento, riqueza, prosperidade, democracia, justiça social; enquanto outras caminham pelo subdesenvolvimento, pobreza, decadência, autoritarismo e desigualdade social.

A cosmovisão analítica desenvolvida conduz ao entendimento de que enquanto a história se constitui como um processo de evolução institucional permanente, a superação do subdesenvolvimento só pode ser alcançada por um processo de ruptura com padrões existentes e envolve, necessariamente, mudanças institucionais, das quais as organizações são os principais agentes. Circunstâncias históricas específicas, de ordem política, econômica ou cultural, podem gerar acontecimentos que impactam as instituições sociais e com isso podem mudar a trajetória de desenvolvimento de uma sociedade.

Cabe a historiografia econômica, nessa trilha aberta por North, pesquisar na história das sociedades os principais condicionantes institucionais de sua trajetória, a conformação de suas matrizes institucionais, fatos que levaram a certas rupturas institucionais e mudanças de trajetória, bem como a participação e os interesses explícitos, ou mesmo velados, dos agentes e das organizações. Enfim, abre-se uma enorme agenda de pesquisas que permite uma releitura de narrativas históricas e um olhar complementar para a história econômica geral.

Um exemplo da forma como a teoria institucional pode ser usada para fins de comparação entre processos institucionais, históricos e econômicos divergentes é a explicação que North encontrou para as diferenças socioeconômicas entre os Estados Unidos e a América Latina. Em sua análise um processo de formação institucional distinto acabou por condicionar trajetórias históricas e de desenvolvimento divergente entre Estados Unidos e América Latina na medida em que enquanto no primeiro foram criadas instituições indutoras do desenvolvimento, na segunda as instituições conformadas determinaram um desempenho social diferente. 
A contribuição de North traz para centro do debate da historiografia econômica e do desenvolvimento econômico a importância das instituições e abre um enorme leque de temas para pesquisas como a cosmovisão de uma sociedade (cultura, hábitos, valores e religião), processo político, teoria do Estado, direitos de propriedade, importância do judiciário e do arcabouço legal, mecanismo de incentivo à inovação, por exemplo.

Indiscutivelmente a teoria desenvolvida por Douglass North renova e revigora a agenda de pesquisas contestando a ergodicidade dos modelos e destacando que a cultura é uma importante chave analítica para a compreensão das trajetórias de desenvolvimento ou subdesenvolvimento das sociedades, e que o Estado possui um papel diferenciado na conformação de adequadas instituições indutoras do desenvolvimento.

Assim, dentro de uma análise histórica do processo de desenvolvimento das sociedades, torna-se fundamental a compreensão de que forma a simbiose dos interesses da burocracia com os dos grupos de pressão externos acabaram dando corpo a determinadas matrizes institucionais, lembrando que na visão desenvolvida por Douglass North o Estado é 0 principal agente capaz de promover mudanças da matriz institucional de uma sociedade e, portanto, alterar a sua trajetória de desenvolvimento.

Em síntese, a teoria das instituições desenvolvidas por Douglass North revigorou 0 campo de pesquisas na historiografia econômica, na teoria econômica, no campo do desenvolvimento, na teoria do Estado e no tocante ao planejamento e gestão de políticas públicas.

\section{REFERÊNCIAS BIBLIOGRÁFICAS}

ABRAMOVAY, Ricardo. Desenvolvimento e instituições: a importância da explicação histórica. In: ARBIX, Glauco; ZILBOVICIUS, Mauro e ABRAMOVAY, Ricardo. Razões e ficções do desenvolvimento. UNESP/EDUSP, 2001.

AZEVEDO, Bonnie. Uma análise antropológica de Douglass North (1973-2009): indivíduo, racionalidade, cultura e instituições. Tese (Doutorado em Políticas Públicas, Estratégias e Desenvolvimento) - Programa de Pós-Graduação em Políticas Públicas, Estratégias e Desenvolvimento, Instituto de Economia, Universidade Federal do Rio de Janeiro (UFRJ), Rio de Janeiro, 2015.

BANCO MUNDIAL. Informe sobre el desarollo mundial: El Estado em un mundo em transformación. Washington: Oxford University Press, 1997.

BOYD, R.; RICHERSON, P.J. Culture and the Evolucinary Process. Chicago: University of Chicago Press, 1985.

FIANI, Ronaldo. Estado e Economia no Institucionalismo de Douglass North. Revista de Economia Política, vol. 23, n. 2 (90), abril-junho, 2003.

GALA, Paulo. A Teoria institucional de Douglass North. Revista de Economia Política, vol. 23, n. 2 (90), abril-junho de 2003a. 
GALA, Paulo. Teoria e Retórica em Douglass North: Subsídios para uma análise de sua contribuição. Dissertação de Mestrado apresentada ao Departamento de Planejamento e Análise Econômica da EAESP/FGV como requisito para a conclusão do Curso de Mestrado. São Paulo: EAESP/FGV, 2001.

HODGSON, Geoffrey H. Lock-in and chreodic development. In.: HODGSON, G.; SAMUELS, W.; TOOL, M. (Ed.). The Elgar companion to institucional and evolutionary economics. Hants: Eduard Elgar, 1994.

LOPES, Herton Castiglioni. Instituições e crescimento econômico: os modelos teóricos de Thorstein Veblen e Douglass North. Rev. Econ. Polit. vol.33 no.4 São Paulo Oct./Dec. 2013. Disponivel em: <www.scielo.br/scielo.php?pid=S0101-31572013000400004\&script=sci_arttext>. Acesso em: 22 de março de 2019.

NORTH, Douglass. Instituições, Mudança Institucional e Desempenho Econômico. São Paulo: Três Estrelas, 2018.

NORTH, Douglass. Understanding the process of economic change. Princeton/Oxford: Princeton University Press, 2005.

NORTH, Douglass. The Role of Institutions in Economic Development: Gunnar Myrdal Lecture. United Nations Publications, 2003a.

NORTH, Douglass. Understanding the process of economic change. In: Forum Series on the Role of Institutions in Promoting Economic Growth, 2003b.

NORTH, Douglass. Instituciones, cambio institucional y desempeño econômico. México: Fondo de Cultura Econômica, 1995a.

NORTH, Douglass. The new institutional economics and third world development. 1995b. Disponível em: <http://www2.econ.iastate.edu/tesfatsi/NewlnstE.North.pdf>. Acesso em 01 de outubro de 2019.

NORTH, Douglass. Institutional Change: a framework of analyses. University Library of Munich, Germany, revised $14 \quad$ Dec $1994 . \quad$ Disponivel em: <https://ideas.repec.org/p/wpa/wuwpeh/9412001.html>. Acesso em: 03 de abril de 2019.

NORTH, Douglas. Desenpeño económico em el transcuso de los años. Estocolmo: (s.n.), Conferência de Douglass North em Estolcomo, Suécia, 09 de dezembro de 1993a. Disponível em: <http://www.eumed.net/cursecon/textos/north-nobel.htm>. Acesso em: 14 de dezembro de 2018.

NORTH, Douglass. Five Propositions about institutional change. Munich: University Library of Munich, 1993b. Disponível em: <https://ideas.repec.org/p/wpa/wuwpeh/9309001.html>. Acesso em 12 de abril de 2019.

NORTH, Douglass. The New Institutional Economics and Development. Washington University in St. Louis, 1992.

NORTH, Douglass. Institutions. Journal of Economic Perspective, 5: 97-112, 1991.

NORTH, Douglass. Instituions, institutional change, and economic performance - political economy of instituions and decisions. Cambridge: Cambridge University Press, 1990.

NORTH, Douglass. Institutions and economic growth: a historical introduction. Word Development, v. 17, n. 9: 1319-1332, september, 1989.

NORTH, Douglass. Structure and Change in Economic History. New York: W.W. Norton, 1981. NORTH, Douglass.; DENZAU, Arthur. Shared mental models: ideologies and institutions. Center for Politics and Economics Claremont Graduate School and Center for the Study of Political Economy. Washington University (St. Louis), 1994. Disponivel em <http://ecsocman.hse.ru/data/957/750/1216/9309003.pdf>. Acesso 13 de abril de 2019.

NORTH, D.C.; MANTZAVINOS, C.; SHARIQ, S. Learning, institutions, and economic performance. Perspectives on politics. Vol. 2. No 1. P. 1-19, 2004. Disponível em: < https://philarchive.org/archive/MANLIA-3>. Acesso em 12 de abril de 2019. 
NORTH, Douglass; THOMAS, Robert. The Rise of the Western Word: A New Economic History. Cambridge: Cambridge University Press, 1973.

NORTH, Douglass C.; WALLIS, John Joseph; WEINGAST, Barry R. A conceptual framework for interpreting recorded human history. National Bureau of Economic Research, 2006. Disponivel em: < http://www.international.ucla.edu/cms/files/north_wallis_weingast.pdf $>$. Acesso em $14 \mathrm{de}$ abril de 2019. [s.d.]

ROBLES, Gustavo A. Prado. El Pensamiento Económico de Douglass C. North. Laissez-Faire, No. 9, 13-32, september, 1998.

RUTHERFORD, M. Institutions in Economics: The Old and the New Institutionalism. Cambridge: Cambridge University Press, 1994.

STORPER, Michael. Las Economias Regionales como Activos Relacionales. Cadernos IPPUR, Rio de Janeiro, Ano XIII, nº 2, 1999.

STRACHMAN, Eduardo. Política Industrial e Instituições. Tese de Doutorado. Instituto de Economia da Universidade Estadual de Campinas, 2000.

Recebido para avaliação em Fevereiro de 2019.

Aceito para publicação em Junho de 2019. 
Teoria das Instituições e da Mudança Institucional de Douglass North: Cultura, Estado e Dependência de Trajetória

\section{Resumo}

Este artigo objetiva analisar os elementos centrais da teoria das instituições e da mudança institucional de Douglass North, em especial o papel que a cultura e o Estado desempenham na determinação de uma trajetória dependente (path dependence). Em sua visão, mudanças culturais evolvendo alterações na cosmovisão dos indivíduos, advindas de alterações na ideologia, religião, crenças e valores, abalam a estabilidade das instituições e tendem a ser importantes vetores de mudança institucional. Ou seja, a cultura materializa-se, em última instância, como a chave para a dependência de trajetória. O Estado, por seu turno, logra a capacidade de promover mudanças institucionais que podem tornar uma economia mais eficiente, garantindo direitos de propriedade e reduzindo custos de transação e incertezas.

Palavras-Chaves: Douglass North, instituições, dependência de trajetória, cultura, Estado.

\section{Abstract}

This article aims to analyze the core elements of Douglass North's theory of institutions and institutional change, in particular the role that culture and the State play in determining a path dependence. In his view, cultural changes evolving changes in the worldview of individuals, arising from changes in ideology, religion, beliefs and values, undermine the stability of institutions and tend to be important vectors of institutional change. That is, culture ultimately materializes as the key to path dependence. The State, for its part, achieves the ability to bring about institutional changes that can make a more efficient economy by guaranteeing property rights and reducing transaction costs and uncertainties.

Keywords: Douglass North, institutions, path dependence, culture, State.

Classificação JEL: B29; B31; B50; E61; H11; K11 